\title{
¿̇Está en crisis la Mediación Intercultural Escolar? Estudio longitudinal desde una visión sociológica
}

\author{
Is Intercultural School Mediation in Crisis? A Longitudinal Study from a \\ Sociological Perspective
}

\author{
Mónica Ortiz-Cobo y Rosella Bianco'
}

\section{Resumen}

La mediación intercultural, como recurso que ha pretendido servir de puente entre «culturas» para favorecer su acercamiento y entendimiento, tiene ya un recorrido histórico que nos permite un análisis retrospectivo de sus prácticas.

Desde este trabajo de corte etnográfico pretendemos evidenciar cómo se ha ido construyendo la mediación intercultural en un ámbito de intervención social, concretamente en las instituciones escolares de la provincia de Granada desde su inicio en 2008. El seguimiento que hemos realizado del recurso durante el periodo comprendido entre 2013 y 2017 en la provincia ha evidenciado lo lejos que han quedado las expectativas iniciales. La implementación de la mediación intercultural escolar ha perdido de vista sus objetivos formales, y ha contribuido a la creación de «diferencias», canalizando procesos de asimilación, etnificación y estigmatización del colectivo inmigrante. Así pues, podemos decir que la gestión escolar de la mediación intercultural ha desaprovechado todo su potencial, llevándola a su devaluación y a una falta de respaldo institucional. Por lo tanto, podemos hablar de una etapa de crisis de la mediación intercultural que va más allá de un descenso de profesionales en activo por motivos de la crisis económica que hace disminuir los recursos económicos en distintos ámbitos sociales.

\section{Palabras clave}

Inmigración, mediación, conflicto, identidad, cultura y escuela.

\section{Abstract}

Intercultural mediation is a resource that has aimed at serving as a bridge between "cultures" in order to favour their approach and understanding. This intervention practice owns already a historical trajectory that allow us to analyse the retrospective of its practices. By this ethnographic work we aim at showing how intercultural mediation has been built in a concrete social intervention field. That is to say, the school institutions of the Granada province since its inception in 2008. The follow-up of the resource, done during the period between 2013 and 2017 in this province, has demonstrated that the fulfilment of the initial expectations has been far from being achieved. The implementation of the school intercultural mediation has lost its formal aims sight of, and has contributed to creating "differences", ending up channelling assimilation processes, ethnification and stigmatisation of the immigrant group. Therefore, we can affirm that the school management of the intercultural mediation has wasted all of its potential, leading it both to its devaluation and a lack of institutional support. Hence, we can talk about a crisis stage of the intercultural mediation that goes beyond the decrease of active professionals due to the economic crisis that diminishes economic resources in different social areas.

\section{Keywords}

Immigration, mediation, conflict, identity, culture and school..

\section{Cómo citar/Citation}

Ortiz-Cobo, Mónica y Bianco, Rosella (2020). ¿Está en crisis la Mediación Intercultural Escolar? Estudio longitudinal desde una visión sociológica. Revista de Sociología de la Educación-RASE, 13 (1), 20-35. http://dx.doi.org/10.7203/RASE.13.1.15765.

\footnotetext{
1 Mónica Ortiz-Cobo, Universidad de Granada, monicaoc@ugr.es; Rosella Bianco, Universidad de Granada, rosellabianco@correo.ugr.es, (corresponding autor).
} 


\section{El conflicto como causa y centro de la intervención de la mediación}

El conflicto es tan antiguo como la propia existencia del ser humano, su vida en sociedad dio paso al surgimiento de los conflictos entre las personas, por situaciones y características distintas, por intereses contrapuestos y necesidades diversas, a menudo enfrentadas. De la existencia connatural de conflictos y de la necesidad de resolverlos surgen distintos mecanismo para gestionarlos. Uno de los modos de abordar el conflicto es la mediación. La palabra mediación se utiliza ya desde el siglo xiII para designar la acción de intervenir entre dos personas o grupos. Tal y como apunta Llevot y Garreta (2012):

«Dicha intervención se podia dar en distintas situaciones, por ejemplo, entre vecinos, familiares por motivos de propiedad y uso de tierra, herencias, o bien entre victimas y personas que habian cometido algún delito y trataban de dictaminar sobre quién recaía la culpa. El medidor era considerado como tal por sus convecinos debido a su prudencia, responsabilidad y sabiduría, razones por las que estos le otorgan su confianza». (Llevot y Garreta, 2012: 168).

Es en el siglo XVIII, concretamente en 1734, cuando aparece por primera vez la voz mediación y mediador en el Diccionario de Autoridades de la Lengua Española. En él se define la mediación como «la interposición o intervención de alguno que pretende componer o reconciliar a otros que están entre sí discordes, o conseguir alguna cosa para otro» (Otero, 2007: 175).

Desde inicios del siglo xx se ha concebido la mediación como un método pacífico de resolución de controversias internacionales, así es reconocida por la Convención de la Haya de 1907, la Carta de Naciones Unidas en 1945 y la Carta de la Organización de Estados Americanos en 1948. La mediación como método alternativo de resolución de conflicto tiene su origen en EEUU, en la década de los 60, donde empezó a utilizarse para solventar los problemas jurídicos de índole laboral, educativo, ambiental y familiar. La mediación permitía y permite reducir costes y tiempo, e incrementar la satisfacción de las partes. A diferencia de los procesos judiciales, donde una parte gana y otra pierde (gana-pierde), en la mediación no hay ganadores ni perdedores, ambas ganan (gana-gana) al ser coparticipes en la solución. Ambas partes son las que llegan a un acuerdo con la ayuda del mediador, que no resuelve el conflicto, ni toma decisiones, sino que facilita la comunicación y el acercamiento entre ellas, siempre desde la neutralidad e imparcialidad. Otros principios que garantizan su eficacia son la voluntariedad y confianza. Por un lado, ambas partes aceptan el proceso de mediación, y son libres de retirarse en cualquier momento, y por otro, la mediación se debe basar en la confianza de las partes en la persona que media y en el proceso.

Unos años después, en los 70, llegó a Europa. Inglaterra fue uno de los pioneros, siguiéndole Francia, Noruega y España. La implantación de la mediación familiar en Europa se lleva a cabo a partir de la Recomendación 1/1998 del Comité de Ministros del Consejo de Europa, en la que se recomienda a los gobiernos de los estados miembros introducir la mediación familiar, promoverla o, en su caso, reforzarla, adoptando y fortaleciendo las medidas necesarias. En España, las comunidades autónomas pioneras en desarrollar sus leyes de mediación familiar fueron Cataluña, Valencia y Galicia (2001). Normativamente a nivel estatal contamos con la Ley 5/2012 de 6 de julio, que regula la mediación en asuntos civiles y mercantiles, y a nivel autonómico, todas aquella leyes de Mediación Familiar.

\section{La mediación en el ámbito de la migración: identidad, cultura y conflicto}

Con la globalización económica y las migraciones, las situaciones de multiculturalidad se han convertido en una realidad frecuente, aunque no se han llegado aún a normalizar como algo natural que discurre en 
una convivencia igualitaria y armoniosa. Es en este contexto en el que se mantiene que la cultura y la identidad intervienen en los conflictos interétnicos. Hennessy (s.f.) plantea el rol de la cultura como aspecto principal para entender y resolver los conflictos, y su relación con la identidad:

\begin{abstract}
"Frecuentemente la cultura pasa desapercibida, no obstante es parte central de la identidad de los individuos y de la metodología por ellos utilizada para crear significación. El conflicto ocurre cuando las identidades y los significados se consideran amenazados, ante lo cual los individuos reaccionan porque les interesa proteger su identidad y todo aquello que les es importante. Como resultado, ellos actúan dentro de los confines de sus matrices culturales, las cuales a su vez, afectan la percepción que ellos tienen de sí mismo y de los demás, así como su comportamiento en el conflicto». (Hennessy, s.f.: 1).
\end{abstract}

En este mismo sentido, Ross (1995) acuña el término «cultura del conflicto». De manera que a la hora de abordar el conflicto y su relación con la cultura podemos hacer una doble aproximación. Por un lado, aquella en la que se identifica cultura con el término identidad o, lo que es lo mismo, la que entiende que la cultura marca la identidad y en esas identidades contrapuestas se da el conflicto. En segunda lugar, podemos entender que la cultura misma influye en el comportamiento que el individuo tiene en el conflicto, no siendo necesariamente la causa del conflicto. En todo caso, para este trabajo debemos subrayar que «la particularidad del conflicto intercultural está en su relación con las diferentes dimensiones de la identidad del ser humano, el cual, al relacionarse con otros, podría dar cabida a una actitud y comportamiento particular que generase una controversia subjetiva. Así la cultura, en algunos casos, ejercería influencia sobre el conflicto» (Pérez, 2007: 119).

La diversidad cultural se construye como parte de la problemática social. De este modo, se ha ido gestando la idea de que buena parte de los conflictos por relaciones entre individuos de culturas diversas debe gestionarse a través de la mediación, concretamente de la denominada mediación intercultural. Pero no es toda la «diversidad cultural» la que la ha motivado, sino aquella que viene dada por la presencia de la inmigración, incluso no toda la inmigración... sino solo aquella ligada a la exclusión y marginación (o que así la representamos) de países extracomunitarios, países considerados «pobres». No es, por lo tanto, la diversidad en sí la causante del malestar social, es la percepción de una gran diferencia en cuestiones como la lengua y la religión, junto con el hecho de que el colectivo que presenta estás diferencias procede de países económicos poco desarrollados y se encuentra en una posición socioeconómica baja y en riesgo de marginación social.

En el ámbito que nos ocupa, el escolar, si bien la diversidad cultural ha estado presente previa a la llegada de alumnado inmigrante extranjero es a partir de este cuando se plantean actuaciones educativas etiquetadas (o más bien erróneamente etiquetadas) como «interculturales». Todas ellas «dirigidas pretendidamente» a reducir las desventajas educativas de este alumnado. Entre estas actuación se encuentran los proyectos de Mediación Intercultural Escolares que son iniciativa de entidades sin ánimo de lucro o pro-inmigrantes que a través de la obtención de una subvención pública contratan a personal mediador para desarrollar actuaciones de mediación que faciliten la integración del alumnado y familias inmigrantes extranjeras. Serán estas prácticas el foco de atención de este trabajo.

\title{
3. Mediación intercultural: más allá del conflicto
}

Tal y como hemos apuntado es en el contexto de las migraciones donde se viene utilizado la llamada mediación intercultural. Por su parte, Giménez (1997) define la mediación intercultural o mediación en 
contextos pluriétnicos o multiculturales como una modalidad de intervención de terceras partes, en y sobre situaciones de multiculturalidad significativa, es decir:

«(...) aquellas en las que la distintividad sociocultural de los actores sociales se convierte, por el motivo que sea, en claramente relevante y central o, al menos, especialmente influyente. En dichas situaciones, los actores sociales en interacción (individuos, grupos, organizaciones, etc.) están dando una importancia considerable -consciente o inconscientemente- a la diferenciación del Otro, en términos físicos, de conducta, de modo de vida, de lengua, de simbolización, de expresión de valores». (Giménez, 1997:133).

Giménez (1997) además destaca como rasgos específicos de la mediación intercultural: a) La naturaleza etnoculturalmente diferenciada de las partes involucradas. En un sistema de intermediación cultural, el punto de partida es que a las personas, grupos o instituciones en él envueltos, se les atribuyen bagajes o identidades culturales diferentes; b) La incidencia de dicha diferenciación en las relaciones existentes entre las partes. Las personas involucradas tienen un cierto conocimiento y desconocimiento del «otro». Los estereotipos, prejuicios y conductas influyen en la relación entre las partes. En este último sentido, Cohen-Emerique (1999) apunta que precisamente las causas de los malentendidos interculturales son dos. En primer lugar, el desconocimiento de los códigos y valores mutuos, lo que constituye una fuente de malas interpretaciones y de incomprensiones. En segundo lugar, la existencia de prejuicios y estereotipos negativos hacia el colectivo inmigrante (también podría apuntarse en sentido inverso) sobre una base de relaciones de dominación y jerarquización, en la que el inmigrante ocupa una posición de inferioridad.

Como apuntamos al principio, el conflicto se ha considerado la causa y centro de la mediación, siendo ésta una intervención reactiva, motivada por la presencia de conflicto. No obstante, en la construcción de la mediación se han incorporado otras visiones que la conciben como un modelo de intervención proactivo, es decir, como un servicio que se presta en situaciones en las que no existe necesariamente conflicto.

Yendo más allá del conflicto, autores como Cohen-Emerique (1997) apuntan tres significados (en definitiva funciones) de mediación:

- El primero se refiere al hecho de servir de intermediario en situaciones en las que no existe conflicto, sino más bien dificultad de comunicación. Se habla entonces de una «mediación preventiva».

- El segundo remite a una situación de conflicto, oposición o antagonismo y está destinada a poner de acuerdo, conciliar o reconciliar a personas o partes. Se trata de una «mediación rehabilitadora».

- El tercero considera la mediación como el proceso por el cual se pasa de un término inicial a un término final, donde apunta a la idea de transformación, en la que se crean nuevas normas y formas relación. En este caso se trata de una «mediación creativa».

En la misma línea Giménez (2002) aporta una definición muy clarificadora, en la que la mediación intercultural es entendida como:

«(...) una modalidad de la intervención de terceras partes neutrales entre actores sociales o institucionales en situaciones sociales de multiculturalidad significativa, en la cual el profesional tiende puentes o nexos de unión entre esos distintos actores o agentes sociales, con el fin de prevenir y/o resolver $y / 0$ reformar posibles conflictos y potenciar la comunicación, pero sobre todo con el objetivo último de trabajar a favor de la convivencia intercultural». (Giménez, 2002: 66). 
La mediación por tanto debe ir más allá de resolver el conflicto, actuando en la prevención del conflicto y transformación las relaciones. Al respecto Giménez (1997: 153) destaca como objetivo de la misma la interculturalidad, entendida ésta como «un proyecto de establecer relaciones interpersonales y sociales en las cuales no se discrimina por motivos de raza, cultura, etnicidad, lengua, religión y nacionalidad, y en las que los sujetos se reconocen como interlocutores, se comunican adecuadamente, se enriquecen mutuamente, etc.» (Giménez, 1997: 153).

\section{Modelos de gestión de la mediación intercultural}

En la gestación de la mediación intercultural podemos apuntar cuatro modelos de mediación, atendiendo a las instituciones u organismos a los que pertenecen el personal mediador (Martínez y García, 2009). Esas cuatro tipologías son:

- Modelo institucional: surge a partir de la demanda establecida desde las instituciones públicas prestadoras de servicios sociales, sanitarios y educativos.

- Modelo asociativo: se da desde las asociaciones y ONGD (Organización No Gubernamental para el Desarrollo).

- Modelo cooperativo: cristaliza en entidades privadas, prestadoras de servicios de mediación bajo diferentes formas jurídicas (ejemplo: «Solomediación» en Olot-Gerona).

- Modelo autónomo: se ejerce a nivel particular como profesional liberal.

El modelo más extendido en España es el modelo asociativo, cuyo servicio suele estar externalizado, pues es prestado por una asociación a través de su personal mediador que es contratado tras la concesión de una subvención en convocatoria pública. Es el caso de la mediación intercultural en contextos escolares. El surgir de este tipo de mediación ha ido acompañado de una figura profesional, la del personal mediador intercultural, que se ha erigido como el elemento clave y necesario para llevar a cabo este tipo de intervención social. Este interviene en contextos inmediatos, mediando entre individuos, grupos o colectivos e instituciones. Combinando estos tres elementos de dos en dos, se pueden distinguir seis tipos de situaciones de multiculturalidad en los que pueden intervenir, tal y como señala Giménez (1997): a) individuo-individuo, d) individuo-grupo; c) individuo-institución; d) grupo-grupo; e) grupo-institución; f) institución-institución. Además, la relación entre dos actores puede ser familiar, laboral, asistencial (acceso a servicios sociales), escolar o médica, judicial o penal, etc. Junto a su contenido o contenidos, cada relación se caracteriza por un conjunto de rasgos en relación con los estatus respectivos, los roles en juego, la existencia o no de conflicto abierto, los niveles jerárquicos de las partes, necesidades en juegos, conductas de las partes, etc. Se trata de notas distintivas que podríamos presentar en forma bipolar, con el hilo conductor de su mayor o menor «verticalidad» u «horizontalidad». Entre las partes involucradas en la relación puede haber un mismo o diferente rol; desigualdad/igualdad; jerarquía/horizontalidad; competencia/cooperación; conflictividad/armonía; voluntariedad/obligatoriedad; dominación/paridad; etc.

\section{Contexto de investigación}

Este trabajo se ha realizado en el contexto de dos proyectos en el marco del Plan Nacional de I+D+i: «Construyendo diferencias en la escuela. Estudios de las trayectorias de las ATAL en Andalucía, de su profesorado y de su alumnado» (CSO2013-43266-R) y «Menores migrantes en el arco mediterráneo: movilidad, sistemas de acogida e integración» (DER2017-89623-R). 
En el desarrollo de la investigación que aquí se presenta hemos empleado como estrategia metodológica la etnografía escolar. Nuestra aproximación al campo de la mediación intercultural en contextos escolares se ha realizado en el periodo comprendido entre 2013 y 2017, concretamente en la provincia de Granada. Para analizar el recorrido del recurso hemos utilizado tanto fuentes primarias como secundarias. Para las primeras hemos recurrido a la entrevista semiestructurada como instrumento de recogida de datos y para las segundas a la revisión de la normativa reguladora de los programas o proyectos de medición intercultural en contextos escolares.

A través de las entrevistas hemos tratado de explorar las experiencias y percepciones de los trabajadores de la mediación. Concretamente en 2017 se entrevistó a todos los profesionales en activo (concretamente tres, dos mujeres y un hombre) y a otra mediadora que, aunque desde 2016 no ejerce como mediadora intercultural escolar, ha sido la profesional con más años de experiencia en la provincia (8 años continuados). El personal mediador en activo en 2017 fue contratado por la Asociación Marroquí para la Integración de los Inmigrantes, la Obra Social Vicente de Paúl y la Asociación Cooperación y Desarrollo con el Norte de África (CODENAF, con sede física en Málaga). La mediadora más veterana, aunque no en activo, estuvo contratada por la asociación Granada Acoge. Nos interesaba contactar con ella pues es una informante clave por sus años de experiencia, pudiendo proporcionarnos una visión retrospectiva. Al hacer referencia al discurso del personal mediador, para diferenciarlos utilizaremos un número (Mediadora 1, Mediadora 2, Mediador 3 y Mediadora 4) y para garantizar su anonimato no los asociaremos a las entidades para las que trabajan, utilizando también un número para diferenciar el discurso de los responsables de las entidades contratadoras (Entidad 1, Entidad 2).

También se procedió a entrevistar al coordinador del área educativa de Granada Acoge y a los responsables del proyecto de mediación de la Obra Social Vicente de Paúl. De la administración educativa se contactó con las responsables de la coordinación de estos profesionales, es decir, con la directora del Equipo Técnico Provincial de Orientación Educativa y Profesional y la Técnico del Área de Compensatoria de la Delegación Provincial de Educación. Este contacto nos permitió identificar a la plantilla de mediadores interculturales que estaban actuando en los centros educativos de la provincia de Granada durante el curso escolar 2016-2017. En esta provincia los programas de mediación intercultural escolar se iniciaron en 2008, desde un modelo asociativo. El número de profesionales y entidades contratadoras ha evolucionado del siguiente modo:

\section{Tabla I. Evolución cuantitativa de la mediación intercultural en contextos escolares}

\begin{tabular}{|c|c|c|}
\hline CURSO ACADÉMICO & NÚMERO DE MEDIADORES & ENTIDADES CONTRATADORAS \\
\hline $2008-09$ & 9 & 9 \\
\hline $2009-10$ & 12 & 10 \\
\hline $2010-11$ & 6 & 6 \\
\hline $2011-12$ & 6 & 6 \\
\hline $2012-13$ & 1 & 1 \\
\hline $2013-14$ & 2 & 2 \\
\hline $2014-15$ & 2 & 2 \\
\hline $2015-16$ & 2 & 2 \\
\hline $2016-17$ & 3 & 3 \\
\hline
\end{tabular}

Fuente: elaboración propia a partir de los datos facilitados por la Delegación de Educación. 
Tal como se refleja en la Tabla I, comprobamos que en los primeros años el número de personal mediador y entidades contratadoras experimentaron sus años de bonanza. No obstante, contrariamente a lo que cabría esperar, la presencia de este recurso ha tendido progresivamente a disminuir, y de un manera brusca desde 2012. Esta evolución decreciente nos lleva a hablar de crisis, pudiendo apuntar como posible causa la propia crisis económica que ha llevado a un descenso en los recursos de manera generalizada. No obstante, consideramos que el germen de la crisis de la mediación intercultural va más allá de lo económico, y responde a una perdida de confianza en sus bondades y potencialidades. En esa falta de apuesta institucional ha sido determinante la propia construcción que se ha hecho del recurso. En este sentido este trabajo trata de deconstruir el recorrido de la mediación intercultural escolar tanto desde la normativa que la regula como de su implementación.

La asociación que mayor presencia ha tenido en este ámbito de intervención social ha sido la asociación pro-inmigrante Granada Acoge, la única asociación sin ánimo de lucro que desde 2008 hasta 2016 ha mantenido su profesional o profesionales, de manera continuada. Es, por tanto, la asociación con más experiencia en la provincia de Granada. De manera intermitente otras entidades han contratado personal mediador para trabajar en el ámbito escolar, a través de la subvenciones de la Junta de Andalucía, como: Cruz Roja, Yanua, Arca Empleo, Proyecto Solidario, Federación de Mujeres Progresistas, Asociación Comisión Católica Española de Migraciones (ACCEM), Asociación IBN Arabi, Federación Andaluza de Asociaciones de Sordos, Save the Children, Asociación de Mediadores Interculturales (ASMIN), Cooperación y Desarrollo con el Norte de África (CODENAF), Asociación Marroquí para la Integración de los Inmigrantes y Obra Social Vicente de Paúl.

\section{6. ¿Qué ha sido de la mediación intercultural y en qué punto nos encontramos?}

Considerando que la mediación intercultural ya dispone de un recorrido que nos proporciona una visión evolutiva, podemos identificar distinto periodos o etapas. Una primera fase de desarrollo (a finales de los noventa principios del 2000) en la que se inician los primeros proyectos de mediación intercultural, que han coincidido con el comienzo de iniciativas formativas que contribuyeron a construir el camino de la profesionalización de la mediación intercultural. Posteriormente se ha experimentado unos años de bonanza, ya entrados unos años en el 2000, etapa en la que los proyectos han proliferado considerablemente, y en que las expectativas de futuro eran muy elevadas, aún en la espera de que este nicho profesional terminase normalizándose y adquiriendo el rango de profesión. No obstante, desde nuestro punto de vista hemos llegado a una tercera fase (a finales de la primera década del 2000) en la que estamos experimentando un retroceso progresivo, donde comprobamos que a pesar del tiempo de rodaje y de las ilusiones, esperanzas y expectativas, estas no se han cumplido y no parece que se vayan a cumplir. Podríamos hablar de crisis de la mediación intercultural. Lo que nos lleva a su plantearnos cuestiones como: ¿Dicha crisis se debe a que ya no es necesaria la mediación o es que nunca lo ha sido? ¿Se debe a una inadecuada gestión del recurso? ¿Las instituciones y entidades sin ánimo de lucro han llegado a saber qué es la mediación intercultural y cómo se debe trabajar? Trataremos de dar respuesta a todas estas cuestiones analizando un caso concreto, el de la provincia de Granada.

\section{Construcción de la diferencia en la normativa que regula la mediación intercultural escolar}

En la Comunidad Autónoma Andaluza la mediación intercultural se encuentra reconocida desde 2001 en el primer Plan Integral para la Inmigración en Andalucía, así como en los sucesivos planes (segundo 
Plan de 2006 y tercer Plan de 2016). En el área socio-educativa de estos planes, se alude a la mediación intercultural de manera general en uno de los tres ejes de actuación, concretamente el eje «Acogida e integración del alumnado inmigrante», donde se recoge la intervención de la mediación en procesos de escolarización, seguimiento e integración del alumnado inmigrante, así como en la sensibilización de toda la comunidad educativa en materia de interculturalidad. En las órdenes que establecen las bases reguladoras para la concesión de subvenciones anuales a entidades sin ánimo de lucro que trabajan en materia de mediación intercultural, se concretan las líneas de actuación (o «conceptos subvencionables»). Dichas órdenes son:

- La Orden de 3 de agosto de 2007, por la que se aprueban las bases reguladoras para la concesión de subvenciones dirigidas a entidades sin ánimo de lucro de ámbito provincial o autonómico para el desarrollo de programas dirigidos a la mediación intercultural, y se efectúa su convocatoria para el curso 2007/2008. BOJA n ${ }^{\circ} 7.22$ de agosto de 2007.

- La Orden 15 de abril de 2011, por la se establecen las bases reguladoras para la concesión de subvenciones a entidades públicas, asociaciones del alumnado y de padres y madres del alumnado y otras entidades privadas en materia de equidad, participación, voluntariado, coeducación, mediación intercultural y absentismo escolar en Andalucía y se efectúa su convocatoria para el curso 2011/12. BOJA no 95, 17 mayo de 2011.

En una primera aproximación a dichas órdenes podemos comprobar que si bien en la orden de 2007, la convocatoria se dirige específicamente a la concesión de subvenciones para programas en mediación intercultural, en la de 2011 se aglutinan siete líneas distintas de subvención (una de ellas la mediación intercultural tanto regional como provincial) descendiendo la cuantía de subvención para dicho programa con respecto a anteriores años. Ello evidencia que los recursos económicos se han ido compartiendo con otros programas, como el de absentismo o coeducación. En este sentido, en la propia normativa quedan reflejadas las etapas evolutivas anteriormente mencionadas: etapa de bonanza en los primero años del 2000 y etapa de retroceso o crisis a finales de la primera década del 2000.

En cuanto a las actuaciones que desde la mediación intercultural se deben desarrollar en contextos escolares, la normativa establece (Orden de 2011):

a) Colaboración y coordinación entre los centros docentes, servicios educativos y entidades del entorno para la integración y el seguimiento escolar del alumnado de origen extranjero.

b) Colaboración con el profesorado de los centros educativos, aportando información especializada para el mejor desarrollo de la tarea docente con este alumnado.

c) Organización de actividades dirigidas a la preparación de las familias inmigrantes en la educación de sus hijos e hijas.

d) Actividades educativas extraescolares de sensibilización intercultural para el alumnado y sus familias, ya sean de origen extranjero o de la sociedad de acogida, así como para el profesorado de los centros.

e) Cualquier otra actividad de mediación intercultural dirigida al alumnado escolarizado en centros docentes públicos. 
La existencia de dichas órdenes pone de manifiesto que el colectivo inmigrante requiere de una intervención «especial y específica»... lo que no contribuye a la normalización del colectivo, que es lo que debería perseguir cualquier política integradora. Más aún, si analizamos en qué se traducen dichas líneas de actuación en las prácticas mediadoras, tal y como se presenta más adelante.

La mediación etiquetada de «intercultural» introduce la diferencia entre lo social y lo intercultural, vinculando lo intercultural a la mera presencia de la población inmigrante. Así pues, la mediación intercultural se ha construido:

1. Sobre el binomio reduccionista «interculturalidad=inmigración», que se sustenta en un concepto erróneo de «diversidad cultural», vinculado a la adscripción étnico-territorial de los individuos.

2. Alejado de un concepto antropológico de cultura, entendida como «cosmovisión de la vida», es decir, forma de pensar, sentir y actuar de los individuos. Desde esta consideración no tiene sentido hablar de una única cultura, aquella que se asocia a una procedencia territorial, sino que podemos hablar de tantas culturas como personas. Por lo que la «diversidad cultural» estaría presente en cualquier grupo humano.

Atendiendo al contenido de las órdenes anteriormente citadas, cabe señalar que en ambas se recoge como una de las actuaciones la «Organización de actividades dirigidas a la preparación de las familias inmigrantes en la educación de sus hijos e hijas», como si las familias inmigrante estuvieran incapacitadas para ello, considerando la diferencia como un déficit. Es por ello que la mediación se ha construido desde un modelo de educación compensatoria y asimilacionista, en lo que profundizaremos más adelante. Por otro lado, en la orden de 2011 se ha eliminado una de las actuaciones recogidas en 2007: «Desarrollo de actividades educativas extraescolares que contribuyan a la integración social y escolar del alumnado inmigrante». En esta se refleja también esa ideología asimilacionista en la que la responsabilidad de la «no integración» recae en el alumnado inmigrante, sin que aparezca la influencia de compañeros, docentes y familias autóctonos, que sin duda tienen un papel fundamental en los procesos de integración. La eliminación de dicha actuación no supone la desaparición de dicha ideología. También identificamos una modificación que dice mucho del lugar que ha ocupado la mediación en los programas educativos. Al respecto, si bien la orden de 2007 establece que se realizarán «Actividades de sensibilización intercultural entre el alumnado, las madres y padres, tanto inmigrantes como de la sociedad de acogida, así como entre el profesorado de los centros», en la posterior de 2011, se especifica que serán actividades de carácter extraescolares. Ello pone de manifiesto el rango que ocupan estas actuaciones, quedando excluidas del currículum ordinario, y adquiriendo un carácter de voluntariedad. Ese cambio en la normativa muestra lo que ha ocurrido en la implementación de la medicación intercultural, las dificultades y limitación que sus profesionales se han encontrado en los centros educativos. Sirva como ejemplo el discurso de la Mediadora 4:

«A menudo es muy complicado que los docentes acepten tus propuestas para realizar actividades... que traten de sacar un tiempo para ello». (Mediadora 4).

«Tu trabajo depende mucho del Orientador... si te abre las puertas o no. Uno me dijo que aqui no necesitamos... y le dije que vale... que yo no pedía limosna, que dejaba el proyecto... y fui a Delegación. Que me ban dicho que no necesitan... y me dijeron que ellos creían que si pero si no quieren... me mandaban a otro centro. Perfecto, yo voy a trabajar, no para estar sentada en una mesa». (Mediadora 4). 
A menudo el profesorado mantiene una perspectiva funcionalista de su labor, en la que la prioridad es cumplir la programación anual y alcanzar los objetivos curriculares. Consideran que no disponen de tiempo para actuación de mediación preventiva (o de «sensibilización»). Entendemos pues que ello ha ido generando tensiones en los contextos escolares y ha quedado reflejado en las modificaciones introducidas en la Orden de 2011.

\title{
8. Construcción de la diferencia en la implementación de la mediación intercultural escolar
}

En las actuaciones de mediación intercultural, anteriormente mencionadas en las órdenes, son tres los sujetos de mediación: alumnado, familias y docentes. Atendiendo a la implementación de la mediación intercultural escolar en la provincia de Granada, desde 2013, hemos podido examinar cómo esta se ha ido configurando, y cómo ha contribuido a la construcción y creación de diferencias. Para ello haremos alusión a las prácticas de mediación intercultural implementadas con alumnado, familias y docentes.

a) Con respecto al alumnado, hemos observado que las actuaciones se dirigen fundamentalmente a una mediación entendida como «preventiva del conflicto» o «sensibilizadora», en la que el mediador propone actividades para mejorar la convivencia (talleres de juegos, lectura, actividades, video-fórum, etc.), tal y como nos explica la Mediadora 1:

\begin{abstract}
«A través de cortometrajes como el Viaje de Said, el Puente, la Convivencia... un cortometraje por sesión, todo para ver cómo afrontar el conflicto y trabajar la resolución de conflictos. Y luego la dinámica del "El antídoto". En esta se sacaría a dos personas, a una se le dice que necesita la cascara de la naranja porque se va a morir un familiar, y a la otra, que necesita el jugo de la misma y tienen que hacer lo posible por conseguirla, a ver como lo resuelven. Siempre pasa que nadie se para a pensar qué necesita cada uno para resolver el conflicto, ya que cada uno necesita una parte distinta de la naranja. Voy a ver qué les parece bien... y si les parece bien seguir buscando cortometrajes. Con los pequeños podría trabajar mediante juegos, pero a ver... También be pensado en poner un buzón de los conflictos que hay, que sea anónimo y ver cómo lo podrían solucionar. Pero claro tengo que hablarlo con el orientador porque si no...». (Mediadora 1).
\end{abstract}

Esta es la propuesta de una mediadora que ha llegado a su puesto hace pocos meses y aún está planificando qué hacer. La Mediadora 1 realizó hace un año el máster propio en mediación de la Universidad de Granada, aunque no cuenta con experiencia previa laboral en este ámbito.

Por otro lado, encontramos otras líneas de actuación, en las que se vinculan el proyecto de mediación intercultural al aula de convivencia ofertado a los centros próximos, tal y como explica la coordinadora de dicho proyecto:

«Tenemos un programa de inmigrantes, otro de empleo y somos aula de convivencia. Los centros de la zona cuando consideran que tiene problemas con un estudiante y lo van a expulsar, nos lo mandan y trabajamos con ellos. En lugar de estar en sus casas están aquí, haciendo sus tareas. Así el proyecto de mediación está vinculado al aula de convivencia, nosotros solicitamos el proyecto por primera vez, y el enfoque que le dimos es de prevención. Planteamos talleres como el de lectura, cocina y juegos. Tratamos de trabajar el aceptar la diversidad, el saber gestionar esa diversidad como prevención». (Responsable del proyecto de mediación en la Entidad 1).

Así pues el aula de convivencia se incorpora al proyecto de mediación, este último es implementado por primera vez por dicha entidad. Al respecto debemos apuntar que, por un lado, el aula de convi- 
vencia nada tiene que ver con la mediación intercultural, ni con la prevención de los conflictos, pese a que así lo vincula la entidad. Por otro lado, esta aula se configura como un espacio de castigo, es decir, de segregación, donde el estudiante debe realizar son tareas de clase de manera aislada. No obstante, las nuevas actuaciones que se han incorporado con motivo del proyecto de mediación intercultural son las actividades denominadas «preventiva», actividades que detalla la Mediadora 2:

«Hemos planteado dos talleres. Uno de juegos, de los juegos que se han jugado toda la vida en el cole pero a través de todas las nacionalidades. Se han buscado juegos de Marruecos, de Hispanoamérica...

Que muchos son los mismos que tenemos aqui, la rayuela, el quema... pero luego cada uno tiene su nombre. Con el mapa del mundo para que se sitúen cada vez que hablamos de un juego. Nosotros lo hemos ofertado a dos colegios, y para si quieren que lo hagamos aqui en la Obra Social o en el centro. En principio, uno lo quiere hacer aqui y otro en el centro. Se les ha ofertado un taller de juegos, de cocina, manualidades, lectura y video-fórum. Todo enfocado al tema multicultural, entonces... el de manualidades era de máscaras del mundo, de Marruecos teníamos uno de pulseras...». (Mediadora 2).

En esta última línea también se dirigen las actuaciones del Mediador 3. Al respecto cabe destacar que este tipo de propuestas de intervención, pese a lo pretendido, no son actividades que tengan un carácter sensibilizador o preventivo del conflicto, incluso contribuyen a cosificar la cultura, y favorece la creación y transmisión de estereotipos, creando y acrecentando las diferencias. Además, no creemos que para la realización de las mismas sea necesaria una intervención del personal mediador, de hecho son actividades ya arraigadas en los centros escolares durante las llamadas semanas interculturales o de las culturas, en las que puntualmente durante una semana se trata de visibilizar las «otras culturas». Si bien es cierto que en muchos centros estas actividades son organizadas por el orientador o/y tutores, en otros se tiende a delegar en aquella figura destinada a atender específicamente al alumnado inmigrantes, como el profesorado de ATAL (Aulas Temporales de Adquisición Lingüística) o mediador intercultural.

En el caso de la Mediadora 2, esta no ha realizado el máster de mediación sino un curso de formación continua en mediación escolar, impartido por el centro de formación del profesorado de la Delegación Provincial de Educación. Así pues, la diferencia entre la primera y segunda propuesta de intervención es notable. El origen de dicha diferencia está sin duda en la formación de origen de las mediadoras. El máster que imparte la Universidad de Granada aborda los distintos ámbitos de intervención (comunitario, familiar, penal, penitenciario y educativo), siendo un contenido específico la mediación en el ámbito intercultural (concretamente, los conflictos por motivos de interculturalidad, habilidades y funciones del personal mediador en el ámbito intercultural). En cuanto a los cursos impartidos por los centros de formación del profesorado de la Delegación de Educación, estos no abordan la perspectiva intercultural, son cursos de unas pocas horas en las que se hace una presentación de la mediación como método alternativo de resolución de conflictos, impartido fundamentalmente para que los centros escolares traten de diseñar programa de mediación dirigido a formar a estudiantes para que actúen como mediadores en conflictos entre iguales. Hablamos pues de un máster profesionalizante frente a curso de formación continua escasamente enfocado al ámbito de la interculturalidad.

Otra línea de actuación que apuntan los profesionales de la mediación es la rehabilitadora, dirigida a resolver los conflictos. En este caso la intervención se da únicamente si uno de los implicados es inmigrante, sin considerar colectivos de otros orígenes étnicos, como el alumnado gitano. Así pues 
se interviene con el alumnado inmigrante por el hecho de serlo, aunque el conflicto no se deba a una cuestión cultural (por ejemplo, por no querer estudiar). Ello contribuye a la etnificación de los problemas, categorizando al inmigrante como sujeto de conflicto y favoreciendo la formación de estereotipos y prejuicios hacia este colectivo. Todo ello supone que dichos conflictos o problemas deben tratarse al margen del aula, de manera excluyente, pues «si hay un especialista para atender al alumnado inmigrante»... «así debe ser»... lo que contribuye a la estigmatización y a la creación de espacios simbólicos de segregación. Sirva como ejemplo lo que nos dice el coordinador del área de educación de una de las entidades que han obtenido subvención, durante ocho años, para desarrollar programas de mediación intercultural escolar (siendo la entidad con más experiencia en la provincia):

\section{«(...) por el hecho de que un chaval sea inmigrante ya no se le incluye en un circuito babitual de re-} currir a la orientación educativa, a un trabajo más amplio, de un diagnóstico... pues no... cae en la mediación intercultural...». (Coordinador del área de educación en la Entidad 2).

Si bien, a menudo, se recurre a la figura mediadora para resolver «problemas» que nada tienen que ver con las diferencias culturales, como ya hemos señalado, en otras ocasiones sí que son conflictos interculturales. Apuntamos como ejemplo lo mencionado por la Mediadora 4:

"Un profesor me reclamaba que un alumno siempre miraba al suelo cuando le hablaba siempre miraba al suelo, y yo le dije que era normal, que era normal porque en nuestra cultura es por el respecto al mayor. Dice que no le respectaba y al contrario. Algunos detalles o pautas que no entienden, tanto a los alumnos como a los profesores». (Mediadora 4).

En este sentido, debemos señalar que en aquellas situaciones en las que la cultura está incidiendo (celebración de fiestas religiosos, menú del comedor o el velo), los centros solicitan la intervención de personal mediador con la intención de que el niño y la familia se adaptan a la cultura hegemónica. Recogemos las palabras de la Mediadora 4:

"Algunos profesores han hecho algún comentario... pero que cada uno haga lo que quiera... Algunos si me han dicho por qué no hablas con... ¿Cómo? no, no... primero no entra en mi trabajo y segundo, no se puede entrar abi porque cada uno... Lo dicen en plan relajado... pero me lo han dicho. Yo me niego a entrar en ese juego, porque no es un juego, es muy grave». (Mediadora 4).

La Mediadora 4 realizó hace ya bastantes años el máster en mediación de la Universidad de Granada, además cuenta con una larga trayectoria como mediadora y es de procedencia marroquí. Todos estas variables influyen en la modo de abordar los conflictos culturales, pues a menudo al personal que ejerce la mediación «no le queda otra»... que acceder a las peticiones de los centros para poder desarrollar sus programas. Entendiendo que son cesiones que ellos hacen para no «cerrarse las puertas» del centro y poder trabajar aunque sea en lo que «les dejen».

b) Con respecto a las familias, las actuaciones son muy limitadas y dirigidas únicamente a las familias inmigrantes. Fundamentalmente la intervención mediadora se da para contactar con ellas por motivos de conductas disruptivas de sus hijos, conflictos o absentismo, así como para facilitar información sobre el sistema educativo. Están ausentes las acciones dirigidas a promover el contacto entre las familias autóctonas e inmigrantes y a sensibilizar a las familias. La intervención para favorecer el acercamiento entre la familia inmigrantes y el centro escolar se realiza en una única dirección, 
siendo las familias inmigrantes las que deben aproximarse y adaptarse a la cultura escolar, a sus requerimientos.

c) En cuanto a las actuaciones con el profesorado se realizan primordialmente las demandadas por los propios docentes, siendo la mediación un recurso a la «carta», al que se recurre para obtener información de los estudiantes o familias y para contactar con ellas por los motivos anteriormente mencionados. Tal y como ocurre con las familias, están ausentes las actuaciones dirigidas a sensibilizar al profesorado (aunque quedan recogidas en la Orden de 2007 y 2011). En este último sentido, las mediadoras reconocen que la intervención con el profesorado resulta difícil, prácticamente inviable, a no ser que se haga de manera muy sutil. Tal y como apunta la Mediadora 4:

«Yo actúo con el profesorado... hablando con ellos en la sala de profesores... pero talleres con ellos no... no están a favor... no veo que... nunca lo he propuesto tampoco. Lo que si hago es hablar con ellos de modo espontáneo sobre aspectos de algunas culturas que no saben... sabias que eso pasa porque...». (Mediadora 4).

«En un centro por ejemplo... del centro que tiene maestras de la vieja escuela, muy majas, pero... que no es que sean racistas... pero no tiene habilidades para hablar... empecé a hablar... a darpautas... Cuando decian mira este negrito... les decía que no se puede decir negrito... este chino muy malo... pero ellas les ayuda no es con maldad». (Mediadora 4).

Consideramos que las actuaciones de sensibilización para el profesorado no tienen una buena acogida porque supondrían, de algún modo, aceptar por parte de los propios docentes que son portadores (e incluso transmisores) de determinadas actitudes prejuiciosas y estereotipos. Si no entienden directamente que «no las necesitan porque no son racistas»... Nosotros mismos lo hemos vivido cuando nos hemos aproximado a los centros escolares para estudiar la gestión del alumnado inmigrante. No han sido pocas las respuestas de tipo «aquí nuestros alumnos están integrados, no hay problemas». Dan por hecho que el interés en el fenómeno migratorio y la escuela es porque «buscamos evidencias de que las cosas no se hacen bien...», desde una perspectiva poco constructiva. Por otro lado, el hecho de que algunas mediadoras opten por una concienciación sutil o latente es porque, primero, la consideran necesaria y segundo, no quieren «cerrarse las puertas de ese centro», por lo que no se atreven a plantear actuaciones planificadas y formales.

\section{Conclusiones}

Atendiendo a las funciones de la mediación intercultural citadas por Cohen-Emerique (1997), hemos comprobado como la función rehabilitadora se ejecuta en situaciones de conflicto, donde hay alumnado inmigrante implicado o simplemente problemas que afecten a dicho colectivo. La función preventiva se limita a actividades aisladas y esporádicas dirigidas únicamente al alumnado en general (nunca a los profesores y familias), con escasa efectividad, que a menudo contribuyen a exacerbas las diferencias. Actividades que, además, se encuentran al margen de un proyecto educativo, por lo que pierden su valor pedagógico. Por último, la mediación no alcanza el rango transformador que permita construir o reconstruir espacios de encuentro y de relaciones armoniosas, que propicie una escuela inclusiva e intercultural. No es de extrañar, pues, que el potencial de la mediación no se haya desarrollado, ni alcanzado el reconocimiento que merece. 
La mediación está a disposición fundamentalmente de los centros escolares que recurren a ella a demanda para resolver «sus problema»... El colectivo inmigrante no suele utilizar la mediación profesional sino la mediación natural o informal ejercida por personas de «confianza» como amigos, vecinos, hijos, etc. La práctica de la medición intercultural escolar, tal y como se ha venido implementado, queda lejos de cumplir los principios sobre los que se debería sustentar. Estos son, los principios de confianza y neutralidad, que resultan difíciles de cumplir cuando las personas implicadas no se relacionan en una situación de paridad sino de desigualdad y jerarquía, y el propio «especialista» en mediación termina interviniendo para que, como hemos dicho, «resuelva los problemas del centro escolar», acatando las decisiones del mismo y siendo un mero trasmisión de dichas decisiones (no como un agente que ayuda a la comunicación y aproximación entre las partes). El alumnado inmigrante y sus familias son agentes pasivos que deben acatar y adaptarse a la cultura dominante, por lo que no son coparticipes de los procesos de mediación, ni se ven involucrados voluntariamente en ellos. Por todo ello, difícilmente se puede dar la premisa «nadie pierde-todos ganan», aquí queda claro quién «gana» y quién «pierde»... Por todo ello, no sorprende la actual etapa de crisis de la mediación intercultural escolar.

Ante los interrogantes que al comienzo nos planteábamos: ¿Esa crisis se debe a que ya no es necesaria la mediación intercultural escolar o es que nunca lo ha sido? ¿Se debe a una inadecuada gestión del recurso? ¿Las instituciones y entidades sin ánimo de lucro han llegado a saber qué es la mediación intercultural y cómo se debe trabajar?, debemos apuntar que, tras seis años de seguimiento de las prácticas de mediación intercultural en los centros escolares de la provincia de Granada, no parece que lo que se haya hecho sea realmente mediación intercultural. La manera de gestionarla y la ideología que la ha sustentado ha llevado a la desvirtualización de dicho recurso. Pero... ¿`es realmente necesaria la mediación intercultural? Consideramos que sí, entendiéndola como «herramienta cotidiana para comprender la diversidad cultural, relacionarse con ella y manejarla» (García y Barragán, 2004: 132). Diversidad, que está presente, adoptando diversas formas, más allá de la inmigración, y que debe ser objeto de la mediación intercultural. Todas las situaciones sociales son multiculturales, desde el momento en que la cultura se comparte de forma diferencial según edades, géneros, clases, religiones, etc. Cuando interactúan dos individuos pertenecientes a una misma cultura, grupo étnico, comunidad religiosa o lingüística, están presentes bagajes, modalidades o versiones siempre diferenciadas. Desde ese supuesto apenas encontramos situaciones sociales de «monoculturalidad».

Desde este enfoque, se propone la mediación no como un espacio profesional concreto, que tenga que depender de una tercera persona, sino como una formación de todos los agentes escolares en una serie de habilidades y estrategias sobre las que poder establecer o restablecer, según los casos, relaciones sociales óptimas, como parte de la socialización escolar, que proporcione un modelo de convivencia adecuado (Ortiz 2006a, 2006b). En este sentido consideramos de interés que la riqueza de la mediación en el contexto escolar está en su valor pedagógico, pues no olvidemos que la:
«(...) escuela es un escenario donde los alumnos inician y consolidan sus relaciones interpersonales, a modo de microcosmos social, y la mediación enseña a participar, gestionar conflictos, asumir compromi- sos, expresar sentimientos y emociones; en suma: contribuye a que los alumnos reciban una formación encontrada en valores y hábitos democráticos». (Martínez et al., 2012: 65).

En todo caso, aunque la mediación se entienda de este modo, en la que no tenga que depender de una tercera persona, no descartamos esta posibilidad, pero como un agente que pueda dinamizar esta forma- 
ción y que intervenga en los procesos de mediación de aquellas situaciones que lo requiera. Siendo dicho agente más que una persona, un equipo compuesto por miembros que representen democráticamente a todos los sectores de la comunidad educativa (profesores, estudiantes, padres y madres). En este sentido, en la necesidad de repensar el modelo de gestión de la mediación intercultural escolar encontramos otras iniciativas, como la de la Comunidad Autónoma de Extremadura, en la que se ha implantado la figura del educador social en los centros educativos de secundaria, integrado en el Departamento de Orientación y ejerciendo la resolución de conflictos y mediación entre otras muchas funciones (control del absentismo escolar, relaciones con la familia, apoyo al profesorado, etc.). En el caso señalado, el proceso de contratación del educador social se inicia en septiembre, exigiéndole la Diplomatura de Educación Social y asociándolo, por lo que respecta a su relación contractual con la Junta de Extremadura, al personal de administración y servicios. Así pues, «sus condiciones laborales se asemejarán a administrativos, conserje y personal de los centros de enseñanza» (Galán, 2008: 57-71). Aunque no sea este el modelo que consideramos ideal sí pone de manifiesto que es posible pensar en otras alternativas de gestión.

\section{Referencias bibliográficas}

Cohen-Emerique, Margalit (1997): "La negociation interculturelle, phase essentielle de l'integration des migrants". Hommes \& Migrations, 1208, 9-23.

Cohen-Emerique, Margalit (1999): "La negociation-mediation, phase essentialle dans l'intégration des migrants et dans la modification des attitudes des acteus sociaux chargés de leur integration". Vie sociale. Les acteurs de l'intégration, 2, 139-155.

Galán, David (2008): "Los educadores sociales en los centros de educación secundaria de Extremadura”. Pedagogía Social. Revista Interuniversitaria, 15, 57-71.

García, Francisco Javier; Barragan, Cristina (2004): "Mediación Intercultural en la sociedad multicultural: hacia una nueva concepción". Revista Portularia, 4, 123-142.

Giménez, Carlos (1997): “La naturaleza de la mediación intercultural”. Revista Migraciones, 2, 125-159.

Giménez, Carlos (2002). El corazón de Madrid. El Servicio de Mediación Social Intercultural. Madrid: Área de Servicios Sociales. Ayuntamiento de Madrid

Hennessy, María Beatriz (s.f.). El rol de la cultura en el conflicto (en línea). https://es.scribd.com/document/88529453/El-rol-de-la-Cultura-en-el-Conflicto, consultado el 7 de Diciembre de 2018.

Llevot, Nuria y Garreta, Jordi (2012): "La mediación intercultural en las asociaciones de inmigrantes de origen africano". Revista Internacional de Sociología, 71 (1), 167-188.

Martínez, María Jesús y García, Rafaela (2009). Análisis y prácticas de la mediación intercultural desde criterios éticos. Valencia: Editorial Tirant lo Blanch.

Martínez, María Jesús; Sahuquillo, Piedad y García, Laura (2012). "Identidad y responsabilidad socioeducativas del mediador escolar y del mediador intercultural: hacia una clarificación de funciones". Revista Mediaciones Sociales, 11, 47-71.

Orden de 3 de agosto de 2007, por la que se aprueban las bases reguladoras para la concesión de subvenciones dirigidas a entidades sin ánimo de lucro de ámbito provincial o autonómico para el desarrollo de programas dirigidos a la mediación intercultural, y se efectúa su convocatoria para el curso 2007/2008. BOJA no 7. 22 de agosto de 2007. 
Orden 15 de abril de 2011, por la se establecen las bases reguladoras para la concesión de subvenciones a entidades públicas, asociaciones del alumnado y de padres y madres del alumnado y otras entidades privadas en materia de equidad, participación, voluntariado, coeducación, mediación intercultural y absentismo escolar en Andalucía y se efectúa su convocatoria para el curso 2011/12. BOJA nº 95, 17 mayo de 2011.

Ortiz Cobo, Mónica (2006a): “'Interculturalidad’ en la mediación escolar”, Revista Portularia, VI (1), 7-16.

Ortiz Cobo, Mónica (2006b): "La mediación intercultural en contextos escolares: reflexiones acerca de una etnografía escolar", Revista Educación, 339, 563-594.

Otero, Milagros María (2007): “Las raíces históricas y culturales de la mediación” en Helena Soleto y Milagros Otero (coords.): Mediación y solución de conflictos. Habilidades para una necesidad emergente. Madrid: Tecnos.

Pérez, Normely (2007): “Interculturalidad: ¿un ámbito de la mediación?”. Portularia, VII(1-2), 107-122.

I Plan Integral para la Inmigración en Andalucía Horizonte 2001. Dirección General e Coordinación de Politicas Migratorias. Consejería de Gobernación. Junta de Andalucía. Fuente: https://www.juntadeandalucia.es/export/drupaljda/1_1843_i_plan_inmigracion.pdf.

II Plan Integral para la Inmigración en Andalucía Horizonte 2006-2009. Dirección General e Coordinación de Politicas Migratorias. Consejería de Gobernación. Junta de Andalucía. Fuente: https://www. juntadeandalucia.es/export/drupaljda/1_1841_ii_plan_inmigracion_0_0.pdf.

III Plan Integral para la inmigración en Andalucía 2016. Consejería de Justicia e Interior. Fuente: https:/ / www.juntadeandalucia.es/export/drupaljda/PIPIA_III.pdf.

Ross, Marc Howard (1995). La cultura del conflicto. Las diferencias interculturales en la práctica de la violencia. Madrid: Paidós.

\section{Notas biográficas}

Mónica Ortiz-Cobos es Doctora Europea en Antropología Social por la Universidad de Granada, profesora del Departamento de Sociología y miembro investigador del Instituto de Migraciones de la Universidad de Granada. Su línea de investigación se centra en el estudio de procesos culturales en contextos educativos diversos. http://orcid.org/0000-0002-8721-1905.

Rosella Bianco es Doctoranda del programa «Estudios migratorios» del Instituto de Migraciones de la Universidad de Granada. Graduada en Comunicación Lingüística Intercultural, por la Universidad de Salento (Italia). Su línea de investigación se centra en el estudio de los procesos de mediación lingüística en contextos de inmigración. http://orcid.org/0000-0002-6327-6464. (Corresponding autor). 